\title{
Abstract Submission CAEP Annual Scientific Assembly June 14-17, 2003
}

\section{Call for Abstracts}

CAEP invites all researchers to submit original clinical or basic research for presentation at the CAEP 2003 Scientific Assembly. The Organizing Committee has worked hard to ensure the research presentations have a high profile at this meeting. Abstracts should represent original research that has

a) not been published or presented at a national (Canadian) scientific meeting, and

b) not been previously published in a paper or online journal or book.

All abstracts must be submitted electronically for receipt on or before February 3, 2003.

\section{Instructions for preparing abstracts}

Please follow instructions. Failure to do so will result in abstract disqualification. Abstracts may be submitted in English or French. The abstract must be typed single space, clear and legible. The abstract must be submitted electronically as follows: Go to CAEP Research Consortium Web site (www.caep.ca/rc). Click on Call for CAEP Abstracts and follow the instructions. Fill in all mandatory boxes. Do not leave empty fields. The abstract must contain, in order: Introduction, Methods, Results, Conclusions, with each heading underlined. Provide the institutional affiliation, city and province of the primary author only. The text of the abstract should be left justified, and maximum length is 300 words. Abbreviations should be kept to a minimum, and defined when first used. Graphs and tables must fit within the abstract box.

\section{Abstract review process}

All abstracts will be peer-reviewed by at least three CAEP abstract reviewers using a standardized evaluation forms. The Research Committee reviewers will be blinded to the authors' name(s) and institutional affiliation(s). Reviewers will not review abstracts from within their own province. Strict conflict of interest declarations will be provided to each reviewer. Abstracts will be selected for oral or poster presentation. Oral presenters will be permitted 10 minutes for their presentation, with 5 minutes for discussion. Posters will be available for viewing in a central location at the convention centre. Notification of acceptance will be transmitted via email or fax no later than Mar. 15, 2003. Consequently, all contact information must be correct at submission. We regret we cannot give notification via telephone.

Complete presentation schedules will be posted on the CAEP (www.caep.ca) and CAEP Research Consortium (www.caep.ca/rc) Web sites. Publication of the original abstract in CJEM will be completed once the abstracts are accepted.

\section{Resident Abstract Competition}

Fujisawa Canada has again agreed to support the Resident Research Competition. CAEP's Research Committee will provide travel funding to 10 residents whose abstract submissions are selected by the Research Committee for this award. Residents must be in a Canadian accredited (CFPC or RCPS) EM programs or have graduated within the previous year (i.e., July 2002). Residents must be the primary investigator and responsible for the project development, the presenter of the abstract (oral) and the first named author. Fellows (Pediatric Emergency Medicine and others) do not qualify for consideration in this competition, unless the research was completed during their EM residency.

\section{Medical Student Abstract Competition}

The CAEP Research Committee will select 5 medical student abstracts for this award. The research must have been performed in a Canadian institution, and the student must be the primary investigator and the person responsible for the project development. They must also be the presenter of the abstract (oral) and the first named author. Note: Potential sources of financial support for medical student travel are currently being investigated. 